\title{
Determination of volatile organic compounds in surface water and sediment using liquid-liquid extraction in selected zones of Asa River, Kwara State, Nigeria.
}

\author{
Oluwadurotimi O. Akiwumi ${ }^{1}$ and Rotimi A. Oderinde ${ }^{2}$ \\ ${ }^{1,2}$ Department of Chemistry, Faculty of Science, University of Ibadan, Ibadan, 23402, Oyo State, Nigeria.
}

\begin{abstract}
This research presents the development of a methodology for analysing volatile organic compounds in selected zones of Asa River, Kwara State. The liquid-liquid extraction procedure of two organic solvent (Hexane : Dichloromethane) $(1: 1 \mathrm{v} / \mathrm{v})$ was employed to remove volatile organic compounds from river and sediment samples, for further identification and quantification showed very good recovery and repeatability. The mean recovery percentage range was between $96.7 \pm 1.5$ - 104.0 1.0 for river samples while $97.3 \pm 2.2$ 104.0 1.0 for sediment samples at a fortification level of $0.01 \mu \mathrm{g} / \mathrm{l}$. In addition, volatile organic compounds were determined by Gas chromatography - mass spectrometry. The limit of quantification was $0.05 \mu \mathrm{g} / \mathrm{l}$ which was below the maximum level allowed by the European council directives for volatile organic compounds $(0.5$ $\mu g / l)$.
\end{abstract}

Keywords: Asa River, Volatile organic compounds, sediment, recovery

\section{Introduction}

Volatile organic compounds (VOCs) are organic chemicals that have a high vapour pressure at ordinary room temperature conditions. Their high vapour pressure results from a low boiling point which causes large numbers of molecules to evaporate or sublimate from the liquid or solid form of the compound and enter the surrounding air. Volatile organic compounds are numerous, varied and ubiquitous [1]. They include both human-made and natural occurring chemical compounds. Volatile organic compounds are primary precursors to the formation of ground level ozone and particulate matter in the atmosphere which are main ingredients of air pollutant referred to as smog. Volatile organic compound emissions result from natural and anthropogenic (manmade) sources [2]. Natural sources of volatile organic compound include vegetation, forest fires, and animals. Although natural sources of volatile organic compounds emissions are larger overall, it is anthropogenic sources in populated and industrialized areas that are the main contributors to air quality problems. The major anthropogenic sources of concern are transportation sector, the use of solvents and solvent containing products, and industrial sources [3]. Harmful volatile organic compounds are typically not acutely toxic but instead have compounding long term effects. Because the concentration is usually low and the symptoms slow to develop, research into volatile organic compounds and their effects is difficult [4].

Liquid-liquid extraction is a method used to separate compounds based on their relative solubility in two different immiscible liquids, usually water and an organic solvent. It is an extraction of a substance from one liquid phase into another and a basic technique in chemical laboratories, where it is performed using a separating funnel [5]. In liquid-liquid extraction there is a feed phase which contains a component to be removed and the addition of a second phase (solvent phase) which is immiscible with feed phase to the solvent phase. After extraction, the feed and solvent phases are called the raffinate (R) and extract (E) phases respectively [6].

Asa River flows through Ilorin in a South-North direction dividing the plain into two, western and eastern parts [7]. Asa River is a major river for economic, environmental and agricultural significance in Ilorin, the capital city of Kwara State, Nigeria. The river receives direct runoff of effluents from industries along its course, apart from domestic wastes and other activities carried out along it that contribute to its pollution [8]. It was pointed out that the river is subject to high level of eutrophication due to organic matter and industrial discharge into it [9]. It was also reported that Asa River catchment was found to have high precipitation and sediment yields when analysed yearly for a period of seven years [10]. Heavy metal and non-metal pollutants have been analysed on Asa River by past researchers. The main focus of this study is to analyse a limitation which has not be reviewed or given attention by any researcher on Asa River, Kwara State that is volatile organic compounds and its hazards to health and environment. This study was carried out to quantitatively analyze volatile organic compounds using liquid-liquid extraction of mixed solvent (hexane and dichloromethane) in river water samples and sediment of Ilorin West Local Government Area [New Yidi/Asa dam zone, Unity Zone and Amilegbe Zone), Kwara State, Nigeria. These areas are highly industrialized and commercialized, also direct discharge of effluents from various companies into water bodies occurs majorly in 
this zones. Concentration at $0.01 \mu \mathrm{g} / \mathrm{l}, 0.02 \mu \mathrm{g} / 1$ and $0.05 \mu \mathrm{g} / 1$ were obtained to generate a good recovery and repeatability. Correlation analysis was done to ascertain interaction between river and sediment samples.

\subsection{Study Area and Sample Collection}

\section{Materials and Methods}

Samples collected from Asa River in Ilorin, Kwara State include New Yidi/ Asa Dam Zone (RW-AS1), Unity Zone (RW-UN-2) and Amilegbe Zone (RW-AM-3) were assessed in this study. Sampling points were selected based on assumed diversity of input from anthropogenic impacts and pollution level. Triplicate samples were taken from each sampling points at interval of four weeks over a period of three months. Preparation of sample bottles and containers is done prior to sampling based on sample size and type of analysis to be performed. Sample containers were thoroughly washed with metal free detergents and rinsed with tap water. They were then soaked in $1 \%$ nitric acid for 24 hours and washed with distilled water and kept intact to prevent contamination. Glass bottles were used to sample Volatile Organic Compounds (VOCs).

Sediment (SD-AS-1, SD-UN-2 and SD-EP-3) at those locations was also collected into treated aluminium foil for Volatile Organic Compounds determination using Ekman grab.

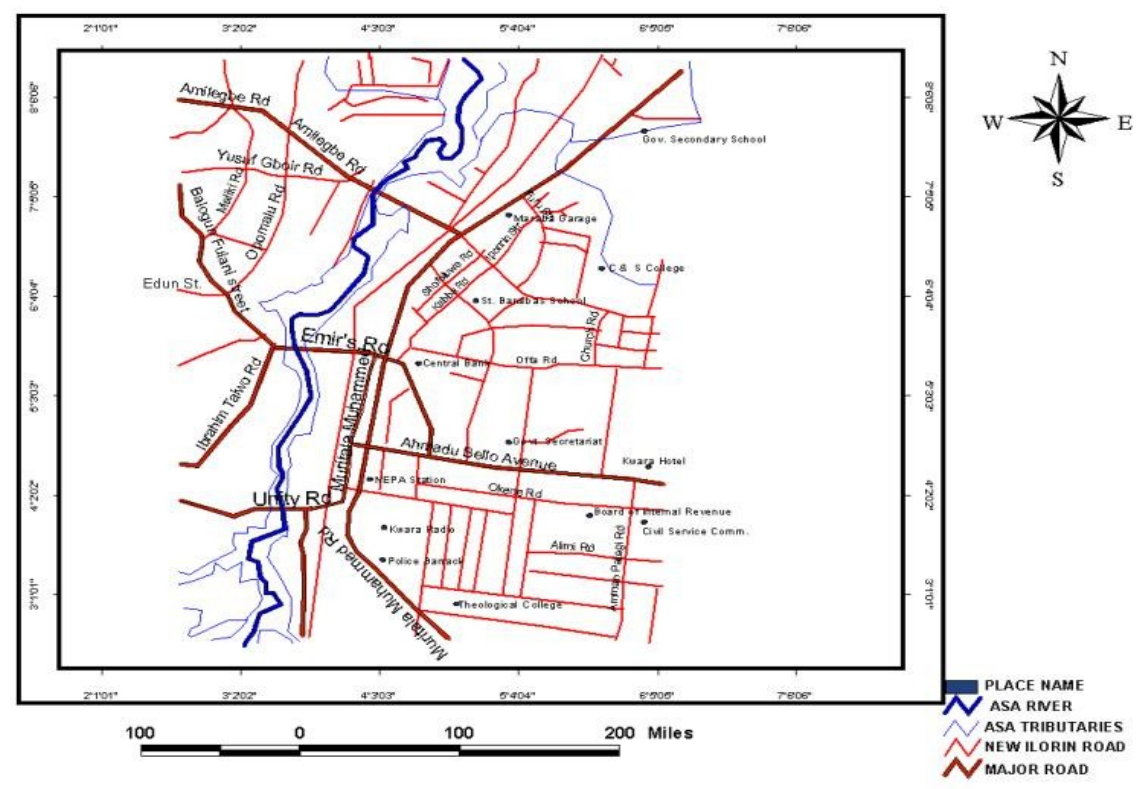

Fig. 1 Extracted Map of Asa River study Area

\subsection{Reagents and solvents}

All chemicals used were of analytical grade. Volatile organic compounds mixed standard include propane, hexane, butane, butene, nonene, decene, benzene, ethanoic acid, ethanedioic acid (New Haven, CT, USA).

Solvents of residue grade purity including dichloromethane, chloroform, $\mathrm{n}$-hexane, 1,2dichlorobenzene, methanol, acetonitrile were obtained from Merck Company. Standard stock solution $0.1 \mu \mathrm{g} / 1$ of mixed volatile organic compounds was prepared in methanol. All solutions were stored in the dark at $4^{\circ} \mathrm{C}$. Working solutions were prepared by dilution of standard stock solution with distilled water.

\subsection{Chromatographic analysis}

Gas Chromatography analyses were performed with a Hewlett-Packard 7890 series gas chromatograph equipped with 5975C Mass Spectrometer detector and splitless injection mode with a pulse pressure of 5.9818psi. Chromatographic separation was carried out using a polar column $(30 \mathrm{~m}$ length, $0.32 \mathrm{~mm}$ i.d., and $0.25 \mu \mathrm{m}$ film thickness). The oven temperature was $250^{\circ} \mathrm{C}$ for 31 minutes followed by temperature programmed to $200^{\circ} \mathrm{C}$ at $17^{\circ} \mathrm{C} / \mathrm{min}$. Helium was used as carrier gas.

\subsection{Water Analysis}

\section{Liquid - liquid extraction procedure}

The industrial and surface water samples were filtered through a membrane filter with $0.45 \mu \mathrm{m}$ pore size before extraction procedures. Water sample of $100 \mathrm{ml}$ was poured into a separating funnel and $100 \mathrm{ml}$ of organic solvent $(50 \mathrm{ml}: 50 \mathrm{ml}$ - hexane: dichloromethane) added and the mixture separated for almost 45 
minutes by thorough shaking, afterwards the extract was poured into a beaker and left for few minutes to evaporate then the remaining extract filtered using cotton wool as a separating medium in a pasture pipette and anhydrous sodium tetraoxosulphate (VI) $\left(\mathrm{Na}_{2} \mathrm{SO}_{4}\right)$ in excess was added to absorbed the remaining water in the sample and this was totalled into a vial bottle up to $2 \mathrm{ml}$ ready for Gas Chromatography analysis.

\subsection{Sediment Analysis}

The dry sediments were carefully collected, homogenized and passed through 60 mesh standard sieves. Sample preparation included homogeneous mixing of $10 \mathrm{~g}$ of sediment with $0.25 \mathrm{~g}$ anhydrous Sodium sulphate to remove moisture and in $10 \mathrm{ml}$ of dichloromethane for $1 \mathrm{~h}$ followed by centrifugation. Then $3 \mathrm{ml}$ of supernatant was filtered through $2 \mathrm{~g}$ of silica gel column with $11 \mathrm{ml} \mathrm{1:1}(\mathrm{v} / \mathrm{v})$ elution of hexane and dichloromethane. The solvent fractions were then evaporated on a rotary evaporator, and exchanged by acetonitrile with a final volume of $2 \mathrm{ml}$ ready for Gas chromatography analysis.

\subsection{Quality Assurance and Quality Control}

\section{Results and Discussion}

The quality assurance and quality control (QA/QC) requirements included establishing Gas chromatography retention times (RT), method detection limit (MDL) and reproducibility for all compounds analyzed. In table 1, forty-six volatile organic compounds are listed along with their molecular weight (MW), boiling point (BP), melting point (MP), method detection limits (MDLs) and relative standard deviation (RSD) of each volatile organic compound. For volatile organic compound collected, method detection limits were between 0.2 and $0.7 \mathrm{ppbv}$. The relative standard deviation was between $0.6 \%$ and $5.0 \%$ which is well within the limit of $\pm 30 \%$. For quality assurance approximately $30 \%$ of the samples were analyzed in triplicate. The reported percentage quality is the amount present in the sample.

Table 1. Properties, Quality Assurance and Quality Control for targeted volatile organic compounds in river and sediment samples

\begin{tabular}{|c|c|c|c|c|c|c|c|c|}
\hline Groups & VOCs Species & MW & $\begin{array}{l}\mathrm{BP} \\
\left({ }^{\circ} \mathrm{C}\right)\end{array}$ & $\begin{array}{l}\mathrm{MP} \\
\left({ }^{\circ} \mathrm{C}\right)\end{array}$ & MDL & RSD & $\%$ Quality & RT \\
\hline \multirow[t]{18}{*}{ Alkane } & 1,1-dichloro 2,2-difluoroethane & 135 & 60 & $\mathrm{n} / \mathrm{a}$ & 0.3 & 3.7 & 91 & 3.327 \\
\hline & BromodichloroMethane & 164 & 87 & -55 & 0.2 & 3.2 & 96 & 3.362 \\
\hline & Trichloromethane & 119 & 60.5 & -63 & 0.5 & 1.5 & 96 & 3.327 \\
\hline & Oxybis[dichloro methane] & 184 & 39.8 & $\mathrm{n} / \mathrm{a}$ & 0.2 & 3.2 & 96 & 3.785 \\
\hline & $\begin{array}{l}\text { 1,2-dimethyl - cis } \\
\text { Cyclopentane }\end{array}$ & 98 & 99 & $\mathrm{n} / \mathrm{a}$ & 0.5 & 1.5 & 62 & 8.992 \\
\hline & $\begin{array}{l}\text { 1,2-dimethyl-trans } \\
\text { cyclopentane }\end{array}$ & 98 & 92 & $\mathrm{n} / \mathrm{a}$ & 0.5 & 1.5 & 62 & 8.992 \\
\hline & Bromomethane & 94 & 4 & -94 & 0.3 & 1.0 & 96 & 10.073 \\
\hline & Methylene cyclobutane & 68 & 42 & $\mathrm{n} / \mathrm{a}$ & 0.5 & 2.0 & 81 & 5.192 \\
\hline & 2-isocyanato propane & 85 & 74 & $<-75$ & 0.3 & 1.0 & 81 & 3.413 \\
\hline & 2-cyclo propyl propane & 84 & 58 & $\mathrm{n} / \mathrm{a}$ & 0.5 & 2.5 & 81 & 3.550 \\
\hline & Ethyl cyclobutane & 84 & 70.7 & $\mathrm{n} / \mathrm{a}$ & 0.5 & 3.6 & 96 & 4.357 \\
\hline & Methyl cyclopentane & 98 & 101 & -126 & 0.5 & 0.6 & 95 & 4.592 \\
\hline & 1,3-dimethyl-cis cyclopentane & 84 & 80.7 & 6.5 & 0.2 & 3.5 & 53 & 9.016 \\
\hline & $\begin{array}{c}\text { 1,3-dimethyl-trans } \\
\text { cyclopentane }\end{array}$ & 98 & 91 & $\mathrm{n} / \mathrm{a}$ & 0.5 & 3.3 & 58 & 9.016 \\
\hline & 2-chloro-1,1,1-trifluoro ethane & 119 & 6.9 & -106 & 0.5 & 3.5 & 91 & 7.144 \\
\hline & 1-methyl-2-octyl cyclo propane & 154 & 203.3 & $\mathrm{n} / \mathrm{a}$ & 0.2 & 3.3 & 62 & 25.975 \\
\hline & 1,2-diethyl cyclo butane & 112 & $\mathrm{n} / \mathrm{a}$ & $\mathrm{n} / \mathrm{a}$ & 0.5 & 2.0 & 73 & 25.975 \\
\hline & 1,3-dimethyl cyclo pentane & 98 & $\mathrm{n} / \mathrm{a}$ & $\mathrm{n} / \mathrm{a}$ & 0.5 & 2.0 & 64 & 8.935 \\
\hline \multirow[t]{16}{*}{ Alkenes } & 2-Pentene $(\mathrm{E})$ & 70 & 37 & -40 & 0.3 & 2.7 & 93 & 3.613 \\
\hline & 2-methyl-1-butene & 70 & 31 & -137 & 0.2 & 1.0 & 93 & 3.648 \\
\hline & 2-pentene & 70 & 37 & $\mathrm{n} / \mathrm{a}$ & 0.3 & 2.0 & 93 & 3.676 \\
\hline & 2-pentene $(\mathrm{Z})$ & 70 & 38 & -180 & 0.3 & 1.0 & 93 & 3.699 \\
\hline & 1,2-dichloro ethene $(\mathrm{Z})$ & 97 & 60.3 & -81 & 0.4 & 1.5 & 57 & 6.697 \\
\hline & 2-Hexene $(\mathrm{E})$ & 84 & 62 & $\mathrm{n} / \mathrm{a}$ & 0.4 & 1.5 & 55 & 6.978 \\
\hline & 3,4-dimethyl-1-pentene & 98 & $\mathrm{n} / \mathrm{a}$ & $\mathrm{n} / \mathrm{a}$ & 0.5 & 1.5 & 77 & 7.464 \\
\hline & 3,7-dimethyl-1-octane & 140 & 156 & $\mathrm{n} / \mathrm{a}$ & 0.5 & 1.0 & 77 & 7.464 \\
\hline & 4-ethenyl cyclohexene & 108 & $\mathrm{n} / \mathrm{a}$ & $\mathrm{n} / \mathrm{a}$ & 0.2 & 2.0 & 53 & 25.855 \\
\hline & 1-Nonene & 126 & 146 & -81 & 0.5 & 1.6 & 65 & 26.038 \\
\hline & 2-butene $(\mathrm{E})$ & 56 & 1 & -105 & 0.5 & 1.0 & 91 & 4.883 \\
\hline & 2-butene $(\mathrm{Z})$ & 56 & 3.7 & -139 & 0.4 & 2.8 & 91 & 4.557 \\
\hline & 2-butene & 56 & $\mathrm{n} / \mathrm{a}$ & $\mathrm{n} / \mathrm{a}$ & 0.3 & 1.5 & 91 & 4.906 \\
\hline & Cycloheptene & 96 & 112 & $\mathrm{n} / \mathrm{a}$ & 0.2 & 0.6 & 57 & 27.840 \\
\hline & 1-chloro-Z-2-heptene & 133 & $\mathrm{n} / \mathrm{a}$ & $\mathrm{n} / \mathrm{a}$ & 0.4 & 4.6 & 50 & 5.740 \\
\hline & 1-Hexene & 84 & 64 & -140 & 0.3 & 1.0 & 90 & 4.929 \\
\hline
\end{tabular}


Determination of volatile organic compounds in surface water and sediment using liquid-liquid

\begin{tabular}{|c|c|c|c|c|c|c|c|c|}
\hline Aromatics & Fluorobenzene & 96 & 85 & -42 & 0.2 & 3.8 & 91 & 6.697 \\
\hline & $2,3,4,5-$ tetrahydropyridine & 83 & $\mathrm{n} / \mathrm{a}$ & $\mathrm{n} / \mathrm{a}$ & 0.4 & 2.5 & 53 & 6.692 \\
\hline & Pyridine-D5 & 84 & 115 & $\mathrm{n} / \mathrm{a}$ & 0.6 & 3.2 & 50 & 6.108 \\
\hline & 2-chlorothiophene & 119 & 127 & $\mathrm{n} / \mathrm{a}$ & 0.7 & 4.4 & 62 & 7.018 \\
\hline
\end{tabular}

Table 1. Contd.

\begin{tabular}{|c|c|c|c|c|c|c|c|c|}
\hline Groups & VOCs species & $\mathrm{MW}$ & $\begin{array}{c}\mathrm{BP} \\
\left({ }^{\circ} \mathrm{C}\right)\end{array}$ & $\begin{array}{c}\mathrm{MP} \\
\left({ }^{\circ} \mathrm{C}\right)\end{array}$ & MDL & RSD & \% Quality & RT \\
\hline & 3-chlorothiophene & 119 & 137 & $\mathrm{n} / \mathrm{a}$ & 0.7 & 3.2 & 62 & 7.018 \\
\hline & Indan-1,2,3-trione & 178 & $\mathrm{n} / \mathrm{a}$ & 250 & 0.5 & 5.0 & 53 & 26.581 \\
\hline & Ninhydrin & 178 & $\mathrm{n} / \mathrm{a}$ & 250 & 0.5 & 2.5 & 62 & 26.581 \\
\hline $\begin{array}{c}\text { Carboxylic } \\
\text { Acids }\end{array}$ & 2,6-diamino-4-hexenoic acid & 144 & $\mathrm{n} / \mathrm{a}$ & $\mathrm{n} / \mathrm{a}$ & 0.3 & 1.0 & 53 & 26.261 \\
\hline & Dichloroacetic acid & 129 & 194 & 9 & 0.3 & 3.8 & 91 & 3.459 \\
\hline & Non-3-enyl ester acetic acid & 184 & 234 & $\mathrm{n} / \mathrm{a}$ & 0.3 & 2.0 & 50 & 28.858 \\
\hline & Fluoroacetic acid & 78 & 165 & 33 & 0.5 & 1.0 & 95 & 7.584 \\
\hline & 2-cyano-ethyl ester hexanoic \\
& acid & 169 & $\mathrm{n} / \mathrm{a}$ & $\mathrm{n} / \mathrm{a}$ & 0.5 & 1.0 & 54 \\
\hline
\end{tabular}

Source: Author's fieldwork

\subsection{Recovery Studies}

Recovery study was performed on investigated compounds from spiked river zone samples and sediment from three zones along Asa River route at three concentration levels. At each concentration level, three determinations were performed. The mean recoveries and relative standard deviation (RSD) of alkanes (pentane), alkenes (butene), aromatics (benzene) and carboxylic acids (acetic acid) can be observed in table 2 and 3 respectively.

\subsubsection{Recovery study on river zones}

Recovery study was done using a known amount of standard volatile organic compounds injected in the sample before extraction to check how much were recovered after completion exercise. The recoveries of volatile organic compounds from spiked river zones were done at three concentrations levels, at each concentration level, three determinations were performed. It was observed at $0.01 \mu \mathrm{g} / \mathrm{l}, 0.02 \mu \mathrm{g} / \mathrm{l}$ and $0.05 \mu \mathrm{g} / \mathrm{l}$ respectively. RW-AS-1 recorded a mean recovery percentage range and relative standard deviation of [97.1 \pm 3.2

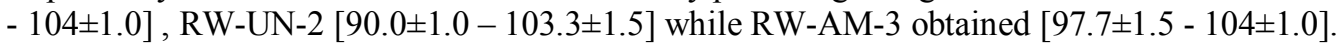

\subsubsection{Recovery study on sediment zones}

The recoveries of volatile organic compounds from spiked sediment was done at three concentration levels, at each concentration level, three determinations were performed. It was observed at $0.01 \mu \mathrm{g} / \mathrm{l}, 0.02 \mu \mathrm{g} / \mathrm{l}$ and $0.05 \mu \mathrm{g} / \mathrm{l}$ respectively. SD-AS-1 recorded a mean recovery range and relative standard deviation of [90.0 $\pm 4.6-102.8 \pm 1.8]$, SD-UN-2 [99.1 $\pm 0.5-104.0 \pm 1.7]$ while, SD-AM-3 [85.0 $\pm 6.6-103.7 \pm 1.2]$.

Table 2. Mean recoveries and standard deviation for river zones sampled

\begin{tabular}{|c|c|c|c|c|}
\hline VOCs & Conc. $(\mu \mathrm{g} / \mathrm{l})$ & RW-AS-1 & RW-UN-2 & RW-AM-3 \\
\hline Alkanes (Pentane) & 0.01 & $101.8 \pm 3.7$ & $102.7 \pm 3.2$ & $100.3 \pm 1.5$ \\
\hline & 0.02 & $97.1 \pm 3.2$ & $96.7 \pm 1.5$ & $97.7 \pm 1.5$ \\
\hline & 0.05 & $104.0 \pm 1.0$ & $99.0 \pm 2.0$ & $104 \pm 1.0$ \\
\hline Alkenes (Butene) & 0.01 & $101.2 \pm 2.7$ & $103.0 \pm 1.0$ & $102 \pm 2.0$ \\
\hline & 0.02 & $102.0 \pm 1.0$ & $103.3 \pm 1.5$ & $98.7 \pm 1.5$ \\
\hline & 0.05 & $103.0 \pm 1.5$ & $95.0 \pm 1.0$ & $103.3 \pm 1.5$ \\
\hline Aromatics (Benzene) & 0.01 & $99.6 \pm 3.8$ & $99.7 \pm 2.5$ & $101.7 \pm 3.2$ \\
\hline & 0.02 & $99.6 \pm 4.4$ & $101.3 \pm 3.2$ & $100.0 \pm 5.0$ \\
\hline & 0.05 & $101.3 \pm 2.52$ & $91.0 \pm 3.61$ & $101.3 \pm 1.5$ \\
\hline $\begin{array}{c}\text { Carboxylic Acids } \\
\text { (Acetic Acid) }\end{array}$ & 0.01 & $102.0 \pm 1.0$ & $99.0 \pm 1.0$ & $102.0 \pm 1.0$ \\
\hline & 0.02 & $102.3 \pm 3.8$ & $103.0 \pm 2.0$ & $99.0 \pm 1.0$ \\
\hline & 0.05 & $103.0 \pm 1.0$ & $90.0 \pm 1.0$ & $100.0 \pm 1.0$ \\
\hline
\end{tabular}


Determination of volatile organic compounds in surface water and sediment using liquid-liquid

Table 3. Mean recoveries and standard deviation for sediment zones sampled

\begin{tabular}{|c|c|c|c|c|}
\hline VOCs & Conc. $(\mu \mathrm{g} / \mathrm{l})$ & SD-AS-1 & SD-UN-2 & SD-AM-3 \\
\hline Alkanes (Pentane) & 0.01 & $97.7 \pm 2.5$ & $101.8 \pm 3.6$ & $98.9 \pm 0.6$ \\
\hline & 0.02 & $97.3 \pm 3.5$ & $99.1 \pm 3.3$ & $103.1 \pm 2.0$ \\
\hline & 0.05 & $99.1 \pm 2.0$ & $105.0 \pm 3.0$ & $92.0 \pm 6.3$ \\
\hline Alkenes (Butene) & 0.01 & $100.0 \pm 2.0$ & $99.7 \pm 1.6$ & $104.0 \pm 1.0$ \\
\hline & 0.02 & $100.3 \pm 2.8$ & $102.6 \pm 1.5$ & $103.0 \pm 0.6$ \\
\hline & 0.05 & $90.0 \pm 4.6$ & $104.0 \pm 1.0$ & $90.0 \pm 1.0$ \\
\hline Aromatics (Benzene) & 0.01 & $101.7 \pm 0.6$ & $104.0 \pm 1.7$ & $100.8 \pm 3.2$ \\
\hline & 0.02 & $102.0 \pm 0.7$ & $99.1 \pm 0.5$ & $99.2 \pm 1.1$ \\
\hline & 0.05 & $85.0 \pm 2.7$ & $102.0 \pm 2.7$ & $85.0 \pm 6.6$ \\
\hline $\begin{array}{c}\text { Carboxylic Acids } \\
\text { (Acetic Acid) }\end{array}$ & 0.01 & $102.7 \pm 2.2$ & $103.7 \pm 0.7$ & $97.3 \pm 2.2$ \\
\hline & 0.02 & $102.8 \pm 1.8$ & $101.6 \pm 1.6$ & $103.7 \pm 1.2$ \\
\hline & 0.05 & $92.0 \pm 5.3$ & $101.0 \pm 2.0$ & $85.0 \pm 8.7$ \\
\hline
\end{tabular}

\subsection{Correlation values of volatile organic compounds based on recovery concentration}

The table 4 shows the correlation analysis for volatile organic compounds targeted at river zones in relation to sediment at the same place. The degree of freedom is 5 , critical table value $=0.754$ at $5 \%$ significance level.

At $0.01 \mu \mathrm{g} / 1$ for RW-SD-AS-1, RW-SD-UN-2 and RW-SD-AM-3 recorded range of $(-0.26-0.30)$, while at $0.02 \mu \mathrm{g} / 1$ for RW-SD-AM-3 was 0.74 which indicated that $r_{\text {cal }}<r_{\text {table }}$ therefore the null hypothesis Ho cannot be rejected and this account show that volatile organic compound of river do not have association with sediment at that concentration. At $0.02 \mu \mathrm{g} / \mathrm{l}$, RW-SD-AS-1 and RW-SD-UN-2 obtained range $(0.76-0.77)$, while at $0.05 \mu \mathrm{g} / 1, \mathrm{RW}-\mathrm{SD}-\mathrm{AS}-1, \mathrm{RW}-\mathrm{SD}-\mathrm{UN}-2$ and RW-SD-AM-3 recorded range $(0.91-0.98)$ and revealed that $r_{\text {cal }}>r_{\text {table }}$ therefore the null hypothesis Ho can be rejected and it would be concluded that there is a positive association between river zone and sediment at those concentration. Figure 1-3 which reveals the correlation analysis pattern at $0.05 \mu \mathrm{g} / \mathrm{l}$ also affirm the interaction between the river and sediment zones. The $\mathrm{R}^{2}$ determine on the graph account for the reliability of the extraction method used based on recovery studies.

Table 4. Correlation variables of volatile organic compounds based on recovery concentration

\begin{tabular}{|c|c|c|c|}
\hline Concentration $(\mu \mathrm{g} / \mathrm{l})$ & RW-SD-AS-1 & RW-SD-UN-2 & RW-SD-AM-3 \\
\hline 0.01 & -0.26 & -0.91 & 0.30 \\
\hline 0.02 & 0.76 & 0.77 & 0.74 \\
\hline 0.05 & 0.91 & 0.98 & 0.96 \\
\hline
\end{tabular}

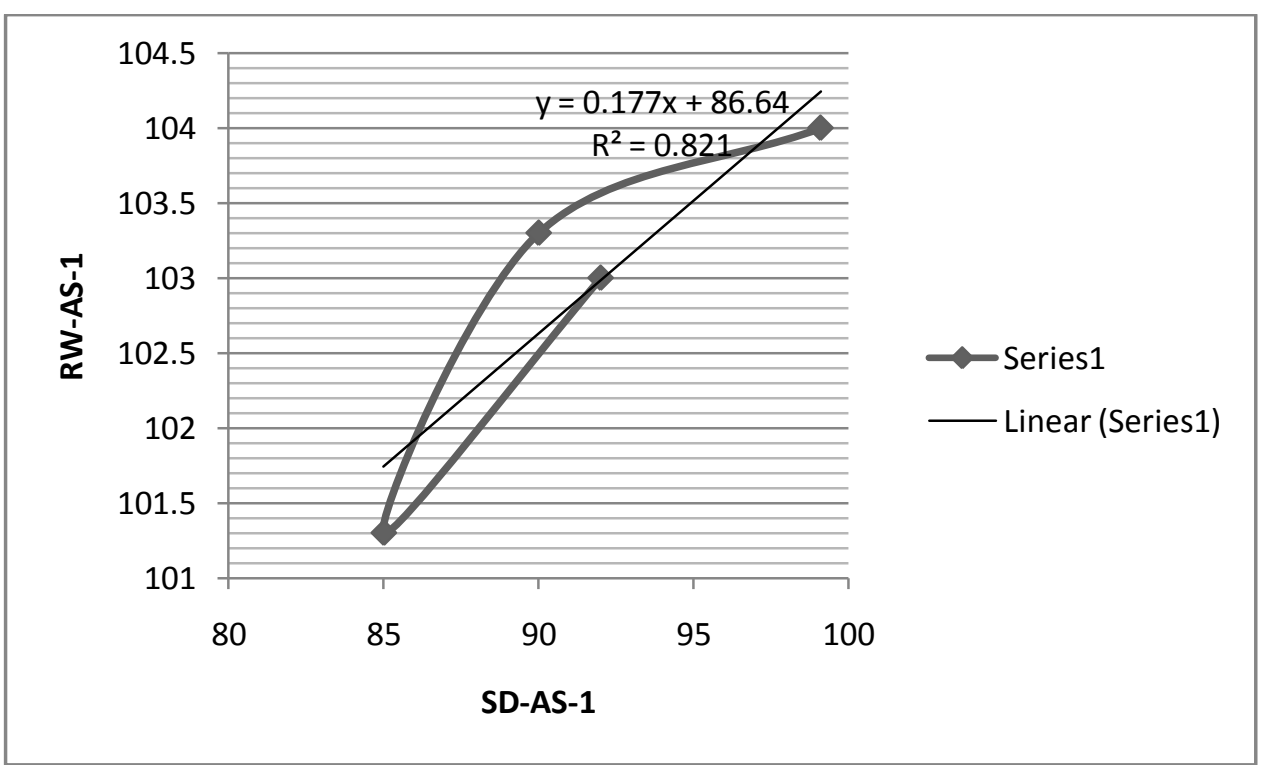

Fig 1. Correlation analysis of river zone and sediment at $0.05 \mu \mathrm{g} / 1$ (RW-SD-AS-1) 


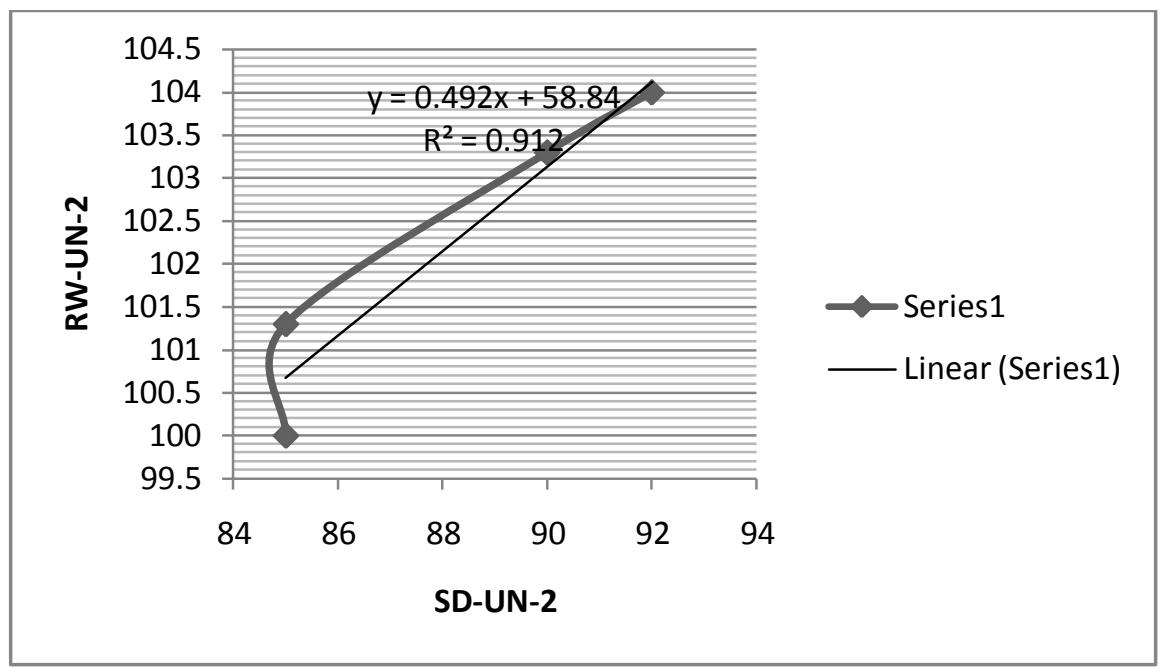

Fig.2 Correlation analysis of river zone and sediment at $0.05 \mu \mathrm{g} / 1$ (RW-SD-UN-2)

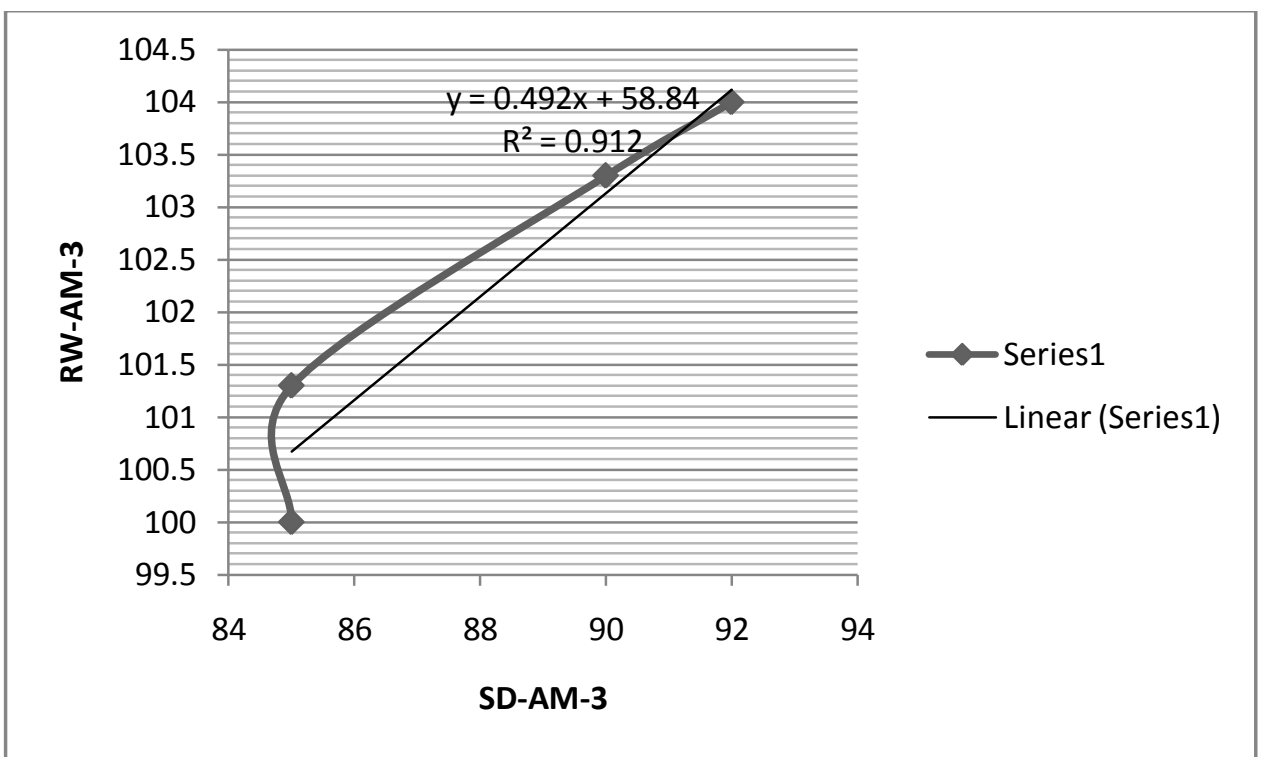

Fig. 3 Correlation analysis of river zone and sediment at $0.05 \mu \mathrm{g} / \mathrm{l}$ (RW-SD-AM-3)

\section{Conclusion}

The extraction method was performed on the river and sediment zones to confirm their applicability on Ilorin environs, Kwara State which had in general a relatively transparent aspect. Previous experiment had shown that the type and volume of solvent could increase the emulsion formation. Therefore, the choice of hexane: dichloromethane was used for liquid-liquid extraction. The recovery experiments were carried out for optimization of liquid-liquid extraction for volatile organic compounds and the following summaries were made: For river samples at $0.05 \mu \mathrm{g} / 1$ recorded $90.0 \pm 1.0 \%-104.0 \pm 1.0 \%$ while sediment samples obtained $(85.0 \pm 8.7 \%-105.0 \pm 3.0 \%)$. Both the river and sediment zones revealed a derivative of benzene (Fluorobenzene) which is a human carcinogen and a chemical compound found in environmental tobacco smoke, stored fuels and exhaust from cars. It has also been found to contaminate food and water and when digested can lead to vomiting, dizziness, sleepiness, rapid heartbeat and at high levels, even death may occur. Other volatile organic compounds like chlorofluorocarbons and chlorocarbons also determined in this experiment are harmful to health and should be thoroughly monitored because this is the river that serves has drinking water source for Kwara state. People who could not afford tap water undergo direct intake through surface water, which could cause the aforementioned health hazards to an individual. Industrial companies which directly or indirectly pour their waste into the water bodies should also be monitored by environmental protection agencies. The effect of volatile organic compounds on human depends on the specific compound, the level of exposure, the timing of exposure and the individual. In summary, though the volatile organic compound gave a good recovery due to their concentration being below limit of quantification, it is evident that the studied area presents a critical situation and offering risks to environmental compartments. 


\section{Acknowledgement}

My unreserved gratitude to my Supervisor, Prof. R.A. Oderinde for his guidance, advice and good contribution to the success of this research. My sincere appreciation to DR.I.A. Oladosu for his advice and guidance during the write-ups. Special thanks to Revd Canon and Mrs M.O. Akiwumi for their moral, financial and parental support in the course of practical work and also to my husband Mr. O.O. Akintade for his love, advice and write-ups correction. God bless you all.

\section{References}

[1] A.H. Goldstein, I.E. Galbally, Known and unexplored organic constituents in the Earth's atmosphere, Environmental Science and Technology. 41(5), 2007, 1514

[2] U. Niinemets, F. Loreto, M. Reichstein, Physiological and physiochemical controls on foliar volatile organic compound emissions, Trends in plant science 9(4), 2004, 180-186.

[3] A.Behr, L. Johnen, Myrcene as a natural base chemical in sustainable chemistry: A critical Review, ChemSusChem 2(12), 2009, 1072-1095

[4] S. Wang, H.M Ang, M.O. Tade, Volatile Organic Compounds in indoor environment and photocatalytic oxidation: State of the art, Environment International 33(5), 2007, 694-705

[5] S.M. Abel, D.Decker and A.K. Vickers, Solvent extraction method, J. Chromatogr. Sci. 32, 1994, 328

[6] E.A. Ibrahim, A.B. Sakla, I.H Suffat, Liquid-liquid extraction, J. Anal. Chem 59, 1987, 2091.

[7] Kwara State of Nigeria, Kwara State Diary, (Government Press, Ilorin, 1997) Nigeria.

[8] A.S. Adekunle and Eniola I.T.K, New York Science Journals 1(1), 2008, 17-21

[9] O.A.A. Eletta, F.A. Adekola, Studies of the physical and chemical properties of Asa River, Kwara State, Nigeria, Science Focus $10(1), 2005,72-76$

[10] H.I. Jimoh, L.I. Alao, Pakistan Journal of Social Sciences 6(1), 2009, 19-25. 